\title{
Práxis educativa: tempo, pensamento e sociedade
}

\author{
Wilson Correia \& Iolanda Carvalho \\ Universidade Federal do Recôncavo da Bahia, Brasil
}

\section{Resumo}

O tema deste artigo é a práxis educativa, pensada mediante a articulação dos conceitos de tempo, pensamento e sociedade. Foi realizado à luz das diretrizes da pesquisa conceitual. Defende a preocupação com a educação do presente para o homem e a mulher concretos, não idealmente concebidos. Analisa os modelos societários capitalista e socialista e preconiza o enfrentamento do desafio de criarmos um modelo societário e um estilo existencial que se baseiem nos valores da justiça e da liberdade, justificativas últimas para que o professor e a professora possam mobilizar os saberes de que são portadores em situações reais de ensino e aprendizagem.

Palavras-chave

Práxis educativa; Tempo; Pensamento; Sociedade

\section{Introdução}

Não serei o poeta de um mundo caduco.

Também não cantarei o mundo futuro.

Estou preso à vida e olho meus companheiros. Estão taciturnos, mas nutrem grandes esperanças.

Entre eles, considero a enorme realidade.

O presente é tão grande, não nos afastemos.

Não nos afastemos muito, vamos de mãos dadas.

(Andrade, 1983, p. 132).

Este trabalho tem por objetivo analisar a temática "Práxis Educativa: Tempo, Pensamento e Sociedade". Busca analisar o quefazer docente 
enfocando-o no presente, em função do qual preconiza que a problematização provocadora do pensar alie sujeitos e sociedade. As fontes deste trabalho são extraídas da literatura especializada na questão educacional, com recorte naquelas que oferecem material conceitual crítico para a investigação da prática do magistério. Este, pois, é um trabalho que cuida da educação praticada atualmente, destinado ao debate nos anos iniciais dos cursos de licenciatura, à qual preconiza desafios em termos de finalidade que, parece-nos, merecem ser enfrentados cotidianamente pelo professor e pela professora. Trata-se de uma pesquisa que se debruça sobre os conceitos de sociedade, pensamento, tempo e saberes docentes, pugnando em favor do emprego da economia epistêmica da magistralidade voltado para as ações transformadoras, críticas e intencionadas da realidade, conceito germinalmente aqui trazido e que, para além do debate em sala de aula, poderá ensejar desdobramentos em outros estudos e investigações.

Primeiramente, este ensaio cuida do conceito de sociedade. Para exemplificar como os humanos criam modelos societários, assinalam-se o capitalismo e o socialismo como exemplos, os quais, historicamente, mostraram-se centralizadores dos valores do individualismo possessivista (Macpherson, 1979) e do coletivismo autoritário (Rocker, 1946), respectivamente. A solução para a saída desses extremos por meio de uma práxis educativa que não se prenda a extremos seria apresentar à educação a tarefa de assumir a incipiente defesa de modelos societários e de estilos existenciais fundados na justiça e na liberdade, de maneira geral e complexa, mas complementar, considerando-se que nosso propósito não é o de oferecermos uma receita sobre como o professor e a professora poderão implementar novos modelos de sociedade, mas provocar o debate e o pensamento a respeito dessa matéria.

Em um segundo momento, este trabalho dedica-se ao estudo sobre o ato de pensar. Nessa seção, destacam-se as atividades cognitivas necessárias à produção de modos de ver o mundo com base na e como produto da atividade que privilegie os atos de analisar, antecipar, classificar, comparar, comprovar, concluir, criticar, prever, provar e sintetizar. Ora, esses são atos aqui propostos como possíveis ao professor e à professora, sobretudo àqueles que vislumbram a possibilidade de desenvolverem a práxis educativa na qual esses atos se tornem mecanismos para se pensar o fazer 
docente. Assim, parece-nos, o ato educativo pode ser a realização fática do pensado, em processo contínuo de problematização, reflexão e compreensão voltados para atividades transformadoras da realidade vivida.

Em seguida, este trabalho empreende o resgate do conceito de tempo. Nesse tópico, tem em vista a possibilidade de a práxis educativa livrar-se de modelos atemporais, extemporâneos ou anacrônicos. Por conta disso, este texto sugere que o trabalho docente se abstenha dos idealismos negadores do presente. Propõe, como consequência desse entendimento, a centralidade à compreensão de que nosso desafio é o que nos indica a concepção e a prática de uma educação do agora para o homem e a mulher de nossos dias, preferentemente crítica e transformadora, para melhor, visando a fazer frente às próprias exigências do processo de educabilidade, exclusivo dos seres humanos, os quais são aquilo no que se fazem pela educação e que nascem e morrem prematuros (Savater, 1998).

Mas como essa práxis, sintonizada com a vida presente, pode ser realizada? Para responder a essa pergunta, este artigo registra a compreensão de que o professor e a professora são os profissionais especializados na "economia epistêmica", inextricável do processo de educabilidade, epistemicidade essa compreendida como aquele conjunto de saberes pesquisados por vários autores da literatura especializada e aqui esquematizados com a finalidade indicativa dos caminhos a serem seguidos nesse campo. Isso faz com que os professores, mais intensa e diretamente, possam lidar com os saberes produzidos pela humanidade e com aqueles de que são portadores na condição docente, sem o qual a práxis educativa se esvazia de sentido e significado.

Aí, então, não se trata de conceber o professor e a professora como aqueles profissionais detentores de uma visão especialiscista que, na condição docente, dedicam-se ao tecnicismo aplicacionista ou ao ativismo pragmatista meramente reprodutores. Antes disso, a tese aqui aventada é a de que os professores são construtores e mobilizadores de saberes vários. Por isso, esses profissionais podem empregá-los visando à humanização das relações pedagógicas em situações reais de ensino e aprendizagem, informando concepções e práticas voltadas para o exercício da inconformidade diante de nossos modelos societários e de nossos estilos existenciais. 
Ora, os saberes dessa economia epistêmica, anteriormente referida, podem ser empregados para se concretizar a práxis educativa que privilegie modelos de sociedade e estilos existenciais baseados na justiça e na liberdade. E isso é um desafio colocado para quem faz e sofre a educação, entendidos como aqueles sujeitos capazes de impulsionar as contribuições educativas aos processos de transformação, para melhor, das nossas reais e atuais condições de vida no mundo e na sociedade. É nesse contexto que a especificidade da ação práxica docente e o que ela pode oferecer em proveito desse desejo pode se tornar uma qualidade da magistralidade possível à professora e ao professor.

\section{Sociedade}

Antes de pensarmos em como podemos abordar a práxis educativa, temos que indagar: $\mathrm{O}$ que é isto, a sociedade? Pela raiz etimológica do termo, sociedade vem do latim societas. Decorre de socius, vocábulo que nomeia o companheiro. E companheiro também deriva do termo latim cumpanere, designando aquele com quem se come do mesmo pão. Companheiro, pois, é ser social. É político. É relacional. Estabelece vínculos. Valora suas relações, dando-lhe sentido ético e intencionalidade, algo que é próprio do humano, o único ser portador do privilégio de vivenciar o processo de educabilidade, pois nasce cem por cento dependente, desenvolve-se gradativamente e, graças à educação, alcança a relativa autonomia característica dos seres racionais, fazendo esse percurso ontoexistencial incrustado no contexto cultural simbólico, apreendendo, na vida e na escola, o modo humano de ser no mundo e no papel de homem ou de mulher.

Assim, para efeito do exercício de pensamento deste trabalho, 'sociedade' é a reunião de seres humanos, sociais e políticos, os quais compartilham costumes, finalidades, gostos, interesses, metas e objetivos. São seres que vivem um estilo existencial e um modo de ser, estar e agir na sociedade e no mundo, mediante maneiras vivenciais mais ou menos criadas, aceitas e socialmente legitimadas, como: "I campo de relações intersubjetivas, ou seja, das relações humanas de comunicação, portanto também: $2^{\circ}$ a totalidade dos indivíduos entre os quais ocorrem essas relações; $3^{\circ}$ um grupo de indivíduos entre os quais essas relações ocorrem em alguma forma condicionada ou determinada" (Abbagnano, 1998, p. 912). 
Um dos caminhos possíveis para entendermos mais concretamente 0 conceito de sociedade é aquele que nos leva a visitar, mesmo que esquematicamente, pelo menos dois modelos societários e os respectivos estilos existenciais que produziram ao longo da história da humanidade: o capitalismo e o socialismo.

O capitalismo pode ser compreendido como modo de produção e sistema social ancorado nos valores da liberdade individual e da propriedade privada, na livre iniciativa e no mercado. Trata-se de uma forma de organização social, ideologicamente justificada pela mundividência liberal. Teve início no século XVI, na Europa Ocidental. Passou pelas fases industrial e mercantil ou comercial, por meio das quais revolucionou a produção material de riquezas, graças ao emprego do tecnocienticismo. Para Karl Marx, o capitalismo é o modo de produção material da vida baseado "no monopólio dos meios de produção e no trabalho assalariado" (Giacoia Júnior, 2009, p. 37), a serviço da mais-valia, do lucro e da acumulação.

A produção capitalista não é apenas produção de mercadoria, é essencialmente produção de mais-valia. O trabalhador produz não para si, mas para o capital. Não basta, portanto, que produza em geral. Ele tem de produzir mais-valia. Apenas é produtivo o trabalhador que produz mais-valia para o capitalista ou serve à autovalorização do capital (Marx, 1982, p. 105).

O capitalismo é um modo de produção material da vida coletiva que tem nas relações assalariadas um de seus elementos principais, o que é possibilitado pela vinculação da propriedade a nomes individuais. Mas, atualmente, além disso, uma característica fundamental do capitalismo é o controle individual do capital, em que

(...) produção de mercadorias; universalização das trocas e, portanto, estabelecimento das relações sociais através da mediação do dinheiro; força de trabalho ("mão-de-obra") assalariada; ausência de controle dos trabalhadores sobre o processo de trabalho. Veja que "lucro" não é uma característica definidora desse sistema. A definição mais sucinta é possivelmente esta: o capitalismo é um regime onde a produção é coletiva e a apropriação (do que é produzido), privada (Figueiredo, 2007, p. 230).

Contrariamente a esses imperativos de natureza econômicoreguladora que potencializam o "individualismo possessivo" (Macpherson, 1979), o socialismo, segundo Giacoia Júnior (2009), nomeia aquele modelo societário inspirado nas ideias de Karl Marx e Friedrich Engels, os quais 
defendem a propriedade pública dos meios de produção, a justa distribuição de bens materiais, a prevalência dos interesses coletivos sobre os individuais e a planificação da atividade econômica. No socialismo não haveria classes sociais, nem propriedade privada. A sociedade controlaria os meios de produção. Riquezas socialmente produzidas não se vinculariam a nomes individuais. Para tanto, Marx e Engels procuraram fundamentar cientificamente suas concepções, defendendo a economia como o motor da história e a luta de classes como o seu combustível primordial. Parece ser essa tese registrada naquilo que veio a se chamar de materialismo históricodialético, no qual o humano produz a própria existência e segundo o qual a realidade capitalista deveria ser transformada rumo ao modelo societário socialista (Durozoi \& Roussel, 1993, p. 317).

Nesse modelo, não seriam a ideia, a mente, a cultura e o espírito que produziriam a realidade, mas, ao contrário, seria a realidade material concreta a fonte das ideias, do conteúdo mental, da cultura e da formação do espírito humano, cuja verdade se realizaria no âmbito da práxis. Segundo Marx,

II - O problema de se ao pensamento humano corresponde uma verdade objetiva não é um problema da teoria, e sim um problema prático. É na prática que o homem tem que demonstrar a verdade, isto é, a realidade, e a força, o caráter terreno de seu pensamento.

O debate sobre a realidade ou a irrealidade de um pensamento isolado da prática é um problema puramente escolástico.

III - A doutrina materialista de que os seres humanos são produtos das circunstâncias e da educação, [de que] seres humanos transformados são, portanto, produtos de outras circunstâncias e de uma educação mudada, esquece que as circunstâncias são transformadas precisamente pelos seres humanos e que o educador tem ele próprio de ser educado. Ela acaba, por isso, necessariamente, por separar a sociedade em duas partes, uma das quais fica elevada acima da sociedade (por exemplo, em Robert Owen).

$X I$ - Os filósofos têm apenas interpretado o mundo de maneiras diferentes; a questão, porém, é transformá-lo (Marx, 1845, pp. 4, 5 e 8).

A leitura das palavras marxianas indica o horizonte práxico como o locus da educação, na qual não apenas o educando é o ser que se educa, mas em meio à qual o ensinante também teria de se educar. Essa educação não seria a do espírito ou do corpo, tomados como instâncias estanques e isoladas no homem e na mulher, mas, sim, uma educação do homem e da mulher em suas integralidades, totalizados como corpo-e-mente, matéria-e- 
espírito, resultado, entre outros, da dialética entre natureza e cultura, humano e mundo.

Aí estão, sucintamente, e a título de exemplo do que chamamos modelos societários, o capitalismo e o socialismo. Entretanto, cabe perguntar: Se, em nome da liberdade individual e da propriedade privada dos meios de produção, o capitalismo termina por sufocar as organizações grupais, cooperativas, coletivas e públicas da vida humana concreta, porque o socialismo, em nome da justiça e da propriedade coletiva dos meios de produção, acaba por asfixiar as liberdades individuais?

Ora, ao pensar sobre essa indagação, entendemos que a morte da dimensão pública da vida tem sido o preço que estamos a pagar para mantermos a liberdade individual descomedida. Essa que é preconizada pela ideologia liberal justificadora do modo de produção capitalista, na qual o estilo existencial reservado ao ser humano é aquele que se configura como o do empreendedor. Por outro lado, a morte das liberdades individuais seria o preço a ser pago para termos a justiça e a propriedade coletiva dos meios de produção, em cujo modelo o estilo existencial proposto à práxis educativa seria a do sujeito que se resigna diante da onipresença estatal. Por isso, analisando um modelo societário e outro, podemos afirmar que a humanidade ainda não foi capaz de conceber um modelo societário consequente e integrador dos dois valores máximos centrados por esses modelos societários, a saber: justiça e liberdade. Porém, criar, propor e defender uma sociedade que conjugue justiça social e liberdade humana parece ser um desafio para a nossa geração, a ser precipuamente enfrentado por quem se fez profissional da educação, sobretudo ao nível compreensivo requerido pela prática docente.

\section{Pensamento}

Pode haver práxis sem a atividade de pensamento? Por entender que não, indagamos: O que é pensar? Os dicionaristas asseguram-nos: o pensamento designa o "Conjunto da atividade mental; representação intuitiva, sensível ou conceitual; ideia" (Giacoia Júnior, 2009, p. 139). Ora, as atividades mentais compreendem, entre outras, as de: perceber, memorizar, praticar uma linguagem, conscientizar-se, associar, avaliar, comparar, compreender, escolher, decidir, interpretar, julgar, refletir e verificar. Por meio desses atos 
cognitivos, representamos o real de maneira sensível, racional e intuitivamente, tornando presente o ausente, e vamos, num movimento contínuo de superação de ignorâncias, pari passu ao surgimento de outras em nós, produzindo conhecimento, criando cultura, realizando a práxis educativa.

Para tanto, esse conjunto de ações mentais resulta em ideias ou formas de ver o existente, conceitual e compreensivamente, o que ganha a forma de mentalidade individual e coletiva. Daí falarmos em cosmovisão, mundividência ou visão de mundo. Pensar, pois, é fundamental ao ato de produzir informações e conhecimentos com vistas para a sabedoria mediadora da relação entre homem e mundo, indivíduo e sociedade. Decisivo ao ato de produzir sentido existencial. Parece ser esse o modo pelo qual o pensamento humano associa-se aos fenômenos mentais, na linha do pensamento cartesiano: "O que é uma coisa que pensa? É uma coisa que duvida, que entende, que concebe, que afirma, que quer, que não quer, que imagina também e que sente" (Descartes, 1997, pp. 1,32). E, ainda:

Pela palavra pensamento entendo tudo aquilo que se faz em nós de tal modo que nos apercebamos imediatamente por nós próprios. É por isso que não somente entender, querer, imaginar, mas também sentir é aqui a mesma coisa que pensar (Descartes, 1997, pp. 1,9).

Ora, parece válido entender essas atividades cognitivas de pensamento como imprescindíveis à compreensão de nós próprios, do outro, do real, no qual "o sujeito é um intérprete que participa do processo ou da realidade cuja estrutura e sentido ele procura apreender, descrever e explicar" (Giacoia Júnior, 2009, p. 46). Por isso, torna-se crucial saber pensar, nomeadamente no âmbito educacional. Sem se dar a esse processo, o que fazer das informações, dos conhecimentos e saberes acessados no percurso da educabilidade? Ora, não é sem motivos que a filosofia, mais especializada na arte de saber pensar, sempre esteve presente em nossos cursos universitários, e, agora, também na Educação Básica brasileira. A função da filosofia tem sido a de problematizar e motivar ao pensamento sobre os outros conhecimentos e a respeito dos modos de ser, estar e agir que eles ensejam.

Isso é crucial porque, segundo Buzzi (2003), com os materiais simbólicos da informação, do conhecimento e do saber, imbuindo-se de propósito e determinação, quem pensa pode analisar. $E$ analisar é a 
capacidade de identificar, descrever e conceituar as partes de um todo, estabelecendo as relações mantidas entre elas, sejam relacionadas a um todo aperceptivo e teórico ou a um todo material e prático. Nesse processo, entremeando a análise, surge a atividade cognitiva denominada comparação. Sem comparar, como estabelecer as semelhanças e diferenças entre as partes de um todo, e mesmo entre fenômenos, coisas, seres e relações? Segue-se daí que quem analisa comparando tem facilitada a tarefa de identificar e determinar as classes a que pertencem os objetos explorados. E classificar só é possível a quem se dedica a criticar, no sentido de separar, julgando e examinando com acuidade cognitiva "o que" pertence "a que" em face dos fenômenos, suas causas e seus efeitos, suas implicações e suas relações.

Todo esse percurso faz sentido quando sabemos que a atividade de pensamento é a que nos garante na tarefa de deduzir. tirar conclusões refletidas e reflexivas sobre os conceitos, ideias, opiniões, objetos, fenômenos, relações, seres e entes pensados, o que se torna possível mediante o entendimento das relações existentes entre partes de um todo e entre coisas, seres e fenômenos aos quais aplicamos nosso espírito. A chegada a conclusões seguras sobre os objetos investigados torna-se o fato que nos possibilita prever e antecipar conseqüências, facilitando-nos a escolha, a decisão e a nossa ação humana no mundo.

Ao abordamos o ato de pensar relacionado com nossa vida, então ocorre de nos parecer plausível a ideia de que toda essa trajetória compreendida nas atividades cognitivas contribui para o ato de sintetizar. A síntese identifica-se com a reconstrução das partes de um todo, de maneira a não nos perdemos no particular, mas articuladas com o geral, assim como o singular deve conjugar-se com o universal, e o uno com o diverso. Isso implica o todo referente ao objeto pensado.

Por fim, essa síntese pode funcionar como prova e comprovação da verdade sobre o objeto de estudo, pesquisa ou investigação. Aí valem os dados, as informações e os aspectos logicamente encadeados que sustentam a compreensão que deve subsidiar nossa decisão, nossa valoração e nosso ser, estar e agir na sociedade e no mundo. E tudo isso, transversalmente, não linearmente compreendido, torna-se imprescindível ao âmbito da educação entendida como atividade práxica e como ação social em cujo processo, nas 
palavras de Paulo Freire, "A prática de pensar a prática é a melhor maneira de pensar certo", uma vez que "O pensamento que ilumina a prática é por ela iluminado tal como a prática que ilumina o pensamento é por ele iluminada" (Freire, 1987, p. 65), em uma práxis educativa que, evitando, de um lado, a mera contemplação, e, de outro, o puro ativismo pedagógico, intente superar a "consciência mágica", suplantar a "consciência ingênua", evitar a "consciência fanatizada" e, por fim, chegar à "consciência crítica" (Freire, 1978; Oliveira, 1996). Sem esse processo, como se dar à práxis educativa, pela qual educando e educador possam se voltar para o trabalho de emancipação antropológica concreta, longe do abstracionismo idealista ou do pragmatismo desprovido de visão?

\section{Tempo}

A práxis educativa aqui pensada não é a que se esgota em um passado que nunca passa, nem em um futuro que nunca chega. Estamos pensando em uma práxis educativa coetânea, hodierna, para o presente, o que nos motiva a perguntar: Como temos compreendido o tempo, nomeadamente no âmbito da filosofia? O que podemos extrair de proveitoso para esta nossa experiência de pensamento daqueles conteúdos fundamentais oferecidos pelos estudos sobre o tempo?

Para respondermos a essas perguntas, voltemos um pouco aos gregos antigos. Ora, sabemos que, na cultura grega clássica, Cronos designa a divindade máxima, pertencente à segunda geração dos seres divinos na mitologia, equivalente ao que Saturno representava para os romanos. Cronos é associado ao tempo pelo fato de também ele devorar os seres e interferir sobre coisas, entes, fenômenos e relações. Ele nasceu de Urano (Céu) e Gaia (Terra). Surgiu como o mais jovem Titã, o qual, para atender a uma solicitação materna, obteve o senhorio das regiões celestes e veio a castrar o próprio pai, casando-se com a irmã Réia, com quem teve seis filhos, os Crónidas, dos quais exterminou cinco. No governo, Cronos foi um rei que conduziu a humanidade a uma era de ouro, mas sempre alimentou o medo de ser destronado e perder o poder, o que o fazia engolir os próprios filhos, já no leito de nascimento. Apenas um, Zeus, não teve tal fim, o qual, crescido entre a terceira geração de deuses, vingou-se de Cronos ao tomar o lugar do pai e alcançar poderio sobre as regiões celestes e de todos os deuses, o que the 
permitiu banir os Titãs para Tártaro, região correspondente ao inferno para o cristianismo (Brandão, 2004).

Pesquisado o material documental e histórico que a tradição nos legou, deparamos com duas abordagens para o tempo: a primeira, iniciada por Aristóteles, compreende o tempo como "número do movimento"; a segunda, ancorada em uma perspectiva subjetiva, fundamenta-se em Agostinho Valério, da Patrística medieval, o qual entendeu o tempo como presente absoluto e que pode ser ampliado pela alma para ganhar a forma trina de passado, presente e futuro. Agostinho indaga: "Qual é o assunto mais familiar e mais batido nas nossas conversas do que o tempo? Quando dele falamos, compreendemos o que dizemos. Compreendemos também o que nos dizem quando dele nos falam" (Agostinho, 1986: XI, 14,17). E esse é um tempo sempre no presente.

O que agora transparece é que não há tempos futuros nem pretéritos. É impróprio afirmar: 'os tempos são três: pretérito, presente e futuro'. Mas, talvez fosse próprio dizer: os tempos são três: presente das coisas passadas, presente dos presentes, presente dos futuros. Existem, pois, esses três tempos na minha mente, que não vejo em outra parte: lembrança presente das coisas passadas, visão presente das coisas presentes e esperança presente das coisas futuras. Se me é lícito empregar tais expressões, vejo então três tempos e confesso que são três (Agostinho, 1986: XI, 20, 26).

Para Kant, já na Modernidade, o tempo, ao lado do espaço, consiste em uma categoria formal a priori da sensibilidade. Ela é pura por não ser proveniente da experiência. Por conta disso, Kant afirma:

Chamo puras (no sentido transcendental) todas as representações em que nada se encontra que pertença à sensação. Por conseqüência, deverá encontrar-se absolutamente a priori no espírito a forma pura das intuições sensíveis em geral, na qual todo o diverso dos fenômenos se intui em determinadas condições. Essa forma pura da sensibilidade chamar-se-á também intuição pura (...). Nesta investigação se apurará que há duas formas puras da intuição sensível, como princípios do conhecimento a priori, a saber, o espaço e o tempo (...). Só no tempo, ou seja, sucessivamente, é que ambas as determinações, contraditoriamente opostas, se podem encontrar numa coisa. Eis porque o nosso conceito de tempo explica a possibilidade de tantos conhecimentos sintéticos a priori quantos os da teoria geral do movimento, teoria que não é pouco fecunda (Kant, 1985, pp. 62, 63 e 72).

Henri Bérgson, por sua vez, estudou os métodos científicos de investigação da intensidade dos estados de consciência. Ele concluiu que só 
é possível atribuir alguma grandeza ao intenso sob a condição de 0 associarmos ao espaço. Nesse processo, normalmente confundimos intensidade com extensidade. O extenso, que é o espaço, penetra outros conceitos, tais como o conceito de tempo. Aí o tempo ganha o status de categoria na categoria, também quantificável, razão pela qual deixa em segundo plano o tempo qualitativo. Um exemplo de Bergson ilustra essa sua abordagem:

Se eu quiser preparar um copo de água com açúcar não tenho outro remédio senão esperar que o açúcar se dissolva. Este fato insignificante tem muito para nos ensinar. Porque o tempo que é necessário esperar já não é o tempo matemático que se aplicaria na mesma ao longo da história inteira do mundo material, caso ela se achasse exposta duma vez só no espaço. É um tempo que coincide com a minha impaciência, isto é, com uma certa porção da minha própria duração, a qual não pode ser esticada nem encolhida a nosso belprazer. Não se trata já do pensado, mas do vivido. Não é uma relação, é o absoluto (Bergson, 1964, pp. 48-49).

Edmundo Husserl estuda a estrutura da consciência do tempo identificado com o "absoluto último e verdadeiro", o fundamento universal da constituição e da totalidade do aparecer fenomenológico. Segundo Husserl, o tempo

(...) é uma designação para uma esfera totalmente fechada de problemas, e de excepcional dificuldade. Será mostrado que nossa exposição de certo modo guardou até agora silêncio sobre toda uma dimensão, e teve necessariamente de guardá-lo, para evitar que se fizesse confusão entre aquilo que só é primeiramente visível na orientação fenomenológica e aquilo que, sem levar em conta a nova dimensão, constitui um domínio fechado de investigações. O 'absoluto' transcendental, que nos preparamos por meio das reduções, não é, na verdade, o termo último, ele é algo que se constitui a si mesmo, em certo sentido profundo e inteiramente próprio, e que tem suas fontes originais num absoluto último e verdadeiro (Husserl, 2006, p. 185).

Outro autor que tenta conciliar as posições aristotélica e agostiniana sobre o tempo é Martin Heidegger, para quem é preciso inverter a ordem em que a tradição filosófica ocidental sempre tratou o tempo (na perspectiva ontológica): em vez de considerar o tempo como presença adjunta à experiência, não mais pensá-lo na perspectiva do ser, mas, sim, de pensar o ser na perspectiva do tempo, "dando o caráter essencialmente temporal do Dasel", o ser-aí, "e de sua compreensão" (Giacoia Júnior, 2009, p. 166). 
Daqui fica patente que a antiga interpretação do ser do ente orientou-se pelo 'mundo' ou 'natureza' em sentido amplo, e que ela de fato conquistou a compreensão do ser a partir do 'tempo'. O documento exterior do que afirmamos - ainda que certamente apenas exterior - é a determinação do sentido do ser (...) que, do ponto de vista ontológico-temporal, significa 'presença'. O ente é apreendido em seu ser como 'presença', isto é, ele é compreendido por referência a um determinado modo do tempo - o 'presente' (Heidegger, 2001, p. 25).

Talvez o tempo realmente merecedor de nossa ocupação seja esse que me permite enxergar a vida concreta à minha volta, ao lado, pessoal e socialmente vivida, a me oferecer a matéria do pensamento e do sentimento, em vista da minha subjetividade e da minha identidade pessoal, profissional e em sociedade. Nesse sentido, a recusa a toda caduquice, que de vez em quando nos ataca, nos faz lembrar Carlos Drummond: "O tempo é a minha matéria, o tempo presente, os homens presentes, a vida presente" (Andrade, 1983, p. 132).

O que estamos querendo dizer com essa citação, uma certeza que transcende a poesia para nos revelar uma posição sobre o tempo? Que talvez uma educação que se alimente do passado não valha a pena; assim como não vale a pena uma proposta educativa delirante e alimentadora de um futuro que resulta de um romantismo ingênuo, mágico ou fanatizado (Oliveira, 1996). A educação na qual acreditamos é uma educação que pode ser solidária no agora, no melhor dos sentidos atribuídos ao termo. Solidariedade vem do latim solidus, a qual significa maciço, implicando a ideia de relacionalidade e vinculidade para qualificar a vida humana, particular e individual, mas também política, coletiva e social. Por que os valores da solidariedade, resultantes do casamento entre justiça e liberdade, não podem consubstanciar nossas práticas educativas atuais?

\section{Práxis educativa}

Uma educação do aqui e do agora. Uma educação que não dissolva o humano no remoto que foi, nem no presumível futuro que será. Educação, não para uma função, para um fazer. Educação, não para uma entrega doutrinal ou ideológica cristalizada. Mas educação do humano para o humano. Uma educação práxica, realmente educativa, crítica e legitimadora daquilo que pode e deve ser legitimado, tanto quanto traidora daquilo que 
merece indiferença e traição, contrariamente aos discursos de nossos dias, os quais nos pedem uma educação para a vivência dos valores estritos da tradição, do ontem, sem ligação com a vida vivida, ou, então, uma educação para a cidadania, para o trabalho, para o mercado, por exemplos. Mas com quê? Quando? Como? Por quem? Para quem?

Um dos caminhos para respondermos a essas indagações é tomarmos o sentido do conceito de práxis para o âmbito da educação. No entanto, temos que indagar: o que é isto, a práxis? Trata-se de um termo implicado no fazer humano. Não qualquer fazer, mas aquele orientado por valores, subentendendo uma concepção ética. Diz respeito, também, a conhecimentos filosóficos e científicos mobilizados ao nível da prática concreta. Práxis compreende princípios e regras posturais e de conduta pessoal e social, entrelaçando teoria e prática, visão e ação. "No marxismo, a práxis tem caráter eminentemente social e não se opõe à teoria, mas é justamente o fundamento dela; no pragmatismo, a práxis é o solo da interatividade entre homem e mundo" (Giacoia Júnior, 2009, p. 146).

Desse modo, práxis é um conceito profícuo à economia epistêmica da atividade docente (detalhada ao final deste estudo), uma vez que, contrariamente ao que fazem certas concepções teóricas, a práxis não promove a dicotomia entre consciência e matéria, teoria e prática, sujeito e objeto, mas os posiciona em contextos relacionais, interativos, interdependentes. E essa perspectiva é interessante, pois ela rompe com idealismos garantidores do entendimento de que a informação, o conhecimento e o saber são criados apenas pela consciência (Hessen, 1980), segundo o qual a educação teria de educar para uma realidade atemporal e fora da vida diária. Ela se distancia, ainda, dos materialismos metafísicos, sustentadores da tese de que o conhecimento é um mero reflexo do mundo exterior à mente humana, indo ao ponto de articular natureza e cultura, o fazer e o pensar (Hessen, 1980), cuja justificativa para a prática educativa assentaria na necessidade de educar seres humanos revolucionários.

Longe de um e de outro extremos, a práxis permite compreender a produção epistêmica e o ato de educar como práticas sociais, realizadas conforme as condições objetivas e subjetivas que homens e mulheres encontram no decorrer da história que protagonizam. Nessa perspectiva, a prática, antes de ser divorciada da teoria, "não só proporciona o objeto do 
conhecimento como também o critério de sua verdade" (Vázquez, 1977, p. 55). Nesse processo, conta o que é vida real e o que homem e mulher são concretamente, como seres ativos e produtivos que não se relacionam com a natureza e com seus objetos de maneira mecânica, mas dialética. É por isso que "toda práxis é atividade, mas nem toda atividade é práxis" (Vázquez, 1977, p. 185), uma vez que práxis é a prática pensada e conscientemente orientada. É aí que se pode visualizar a importância da práxis no processo de produzir conhecimento por meio da pesquisa, tanto quanto mobilizar o saber produzido nos processos de investigação epistêmica no ensino e nas ações concretas em meio à sociedade, à realidade, incessantemente investigadas pelos profissionais da educação. Nesse processo, segundo Marx,

É mister, sem dúvida, distinguir, formalmente, o método de exposição e o método de pesquisa. A investigação tem de apoderar-se da matéria em seus pormenores, de analisar suas diferentes formas de desenvolvimento, e de perquirir a conexão íntima que há entre elas. Só depois de concluído esse trabalho é que se pode descrever, adequadamente, o movimento real. Se isto se consegue, ficará espelhada, no plano ideal, a vida da realidade pesquisada, o que pode dar a impressão de uma construção a priori (Marx, 1982, p. 16).

O que Marx propõe é o método dialético no trabalho de produzir e fazer circular o conhecimento. Isso requer que o conhecimento da realidade não ocorra de maneira mágica, ingênua ou espontânea (Oliveira, 1996), mas de modo crítico e interacional entre sujeito e objeto, em que particular e universal, teoria e prática se imbriquem de maneira inextricável, no movimento contínuo de afirmação, negação e síntese reconstrutiva. É nesse sentido que podemos compreender o trabalho docente na perspectiva práxica.

Práxis é a atividade concreta pela qual os sujeitos se afirmam no mundo, modificando a realidade objetiva e, para poderem alterá-la, transformando-se em si mesmos. É a ação que, para se aprofundar de maneira mais conseqüente, precisa de reflexão, do auto-questionamento, da teoria; e é a teoria que remete à ação, que enfrenta o desafio de verificar seus acertos e desacertos, cotejando-os com a prática (Konder, 1993, p. 115).

Note que o exposto até aqui nos indica que o trabalho docente implica um saber entrelaçado a um fazer, cuja associação torna-se o locus da gênese do cânone da magistralidade particular do professor e da professora. Diversos autores, empregando variadas teorias (Forquin, 1992, 1993; Freire, 1997; Garrido, 1999; Libâneo, 2002; Libâneo, Oliveira, \& Toshi, 2004; Monteiro, 2001; Nóvoa, 1991, 2005; Perrenoud, 2000; Romanovski, 2007; Saviani, 
2003; Tardif \& Raymond, 2000), dedicam-se a estudar a questão do saber e do fazer docentes, tendo em comum a concordância sobre a existência do saber e do fazer como características marcantes da profissão de professor.

O saber aqui entendido não é o que idealmente se poderia imaginar desligado da ação prática. Ao contrário, ele qualifica o agir docente. Por isso, ele é práxico, à medida que oferece conteúdo, intencionalidade, objetivos e metas às atividades daqueles que lidam com o planejamento, a execução e a avaliação do ato educativo. Esse saber aqui arrolado faz-se ponte, mediação e condição de possibilidade do quefazer professoral, qualificando os vínculos humanos e as relações com o mundo natural e da cultura que os e as ensinantes experienciam na condição de sujeitos produtores de bens simbólico-culturais.

É exatamente a construção desse saber que requer a atribuição de sentidos ao tempo e ao pensar, tendo em vista a formação de seres humanos para a vivência de estilos existenciais no seio da sociedade. Perguntas como "Que ser humano educar?" e "Que modelo societário preconizar?" implicam problemas que, consciente ou inconscientemente, a práxis educativa responde, bem ou mal, ao menos em nível compreensivo, mas que também pode qualificar a vida concreta dos sujeitos sociais envolvidos com seus processos. Nisso, o trabalho do ensinante guarda compartilhamento de sentido com o de educar exercido por pais, líderes religiosos, autoridades públicas e demais adultos que, de algum modo, contribuem para a inserção do novato humano no processo da educabilidade e ascensão à cultura, ao modo humano de existir.

Desse modo, tendo em vista as contribuições teóricas críticas aqui registradas, compreendemos que o professor e a professora podem ser concebidos como aqueles profissionais que portam um conjunto de saberes, os quais nós, autores deste artigo, podemos denominar de: Saber Antropológico, Saber Cultural, Saber Econômico, Saber Epistêmico, Saber Ético, Saber Ideológico, Saber Político, Saber Profissional, Saber Social e Saber Vivencial, constituintes da economia epistêmica professoral com potencialidade de informar uma docência práxica e consequente ao nível técnico, metodológico e político, articulando tempo, pensamento e vida social.

O Saber Antropológico é proveniente da antropologia. Esse campo geral do saber investiga a condição humana no mundo, inserida na natureza 
e na cultura, com destaque para seus aspectos físicos e simbólicos, implicando a pesquisa e a criação de sentidos para crenças, critérios de ação, linguagens, psiquismo, relações humanas e valores, dentre outros. O professor e a professora podem se apropriar desse saber em sua educabilidade global, que se estende do nascimento à morte e que lhe dá um estilo existencial a ser vivido em meio a um modelo societário determinado (cf. Laplantine, 1989).

O Saber Cultural resulta do processo de produzir cultura e de the atribuir sentido. Nisso, vale a ideia de que o humano é um ser de ação. Ao agir, como nos ensina o pensamento marxiano, ele produz o próprio modo de ser no mundo, constituindo um patrimônio cultural e simbóllico indicador daquilo que ele é, como ser que se diferencia da realidade natural bruta e intocada por qualquer outro ser. A apropriação desse conhecimento cultural pelo professor e pela professora pode ser dar por meio da inserção desses sujeitos nos processos da educabilidade informal oral e informal letrada, os quais oferecem subsídios sobre ser-estar no e sobre o interagir com o mundo (cf. Jameson, 1995).

O Saber Econômico tem sua fonte nas vivências humanas relacionais que são mediatizadas pela teoria do agir econômico e pela praxiologia da ética econômica. Aqui são criados os materiais compreensivos sobre valor de uso e uso do valor, tanto quanto a respeito do que sejam dinheiro, produtividade, relações de troca, relações produtivas e riquezas. Ter ou não ter dinheiro e ganhar um salário bom ou ruim, por exemplo, são aspectos da vida prática que se situa no âmbito dessa temática. Os professores se voltam à apropriação desse saber mediante as relações econômicas mantidas com outros seres humanos, na vida, no ambiente de trabalho e assemelhados (cf. Schumpeter, 1982).

O Saber Epistêmico específico refere-se às diferentes modalidades de saber produzido pelo homem e pela mulher, no plano teórico e no plano prático. Historicamente, essa construção passa pelas modalidades de saber que os homens produzem, incluindo artes, ciência, filosofia, mito, saber da vida, tecnologia e teologia, bem como dos recursos técnicos criados pelo homem e pela mulher para realizarem a interação com o mundo (cf. Hegenberg, 1976). Professores e professoras podem adquirir esse saber ao longo da existência mesma, percorrendo as trilhas naturais da vida em sociedade. 
O Saber Ético relaciona-se ao modo como o homem e a mulher criam seus estilos existenciais baseados em valores e critérios de ação. Ele responde a indagações sobre como se deve agir. Especificamente, sua problematização envolve as seguintes indagações: "O que devo fazer?" (Kant, 1985), "O que posso fazer?", "O que nos obriga a sermos bons?" (Cabanas, 1996). O professor e a professora adquirem esse saber mediante experiências valorativas nas quais se inserem ao longo da vida e da ação pósvaloração, julgamento, decisão e ação nos diversos âmbitos da vida concreta (cf. Vázquez, 1977).

O Saber Ideológico é aquele que deriva da experimentação de materiais simbólicos e compreensivos voltados para a justificativa de modelos societários e estilos existenciais que legitimam conceitos e modos de ser, conforme se entende o que sejam papéis sociais, de raça e de sexonormatividade, entre outros, constitutivos disso que podemos denominar de mentalidade particular e socialmente compartilhada. Nesse sentido, tratase de conteúdos mentais que formam a mundividência, qualificada por valores, os quais oferecem as diretrizes do ser, estar e agir na sociedade e no mundo. Torna-se plausível a aquisição desse saber pelos professores à medida que vivem como seres sociais o dia a dia da existência em meio aos semelhantes (cf. Althusser, 1983; Chauí, 2003; Gramsci, 1981; Marx \& Engels, 1987).

O Saber Político deriva das experiências com o modo como criamos, instauramos e legitimamos práticas de poder em meio à sociedade. Relaciona-se com a forma como estabelecemos modos de vida entre os diferentes, uma vez que os humanos são múltiplos e plurais, mas se organizam em cidades que são governadas conforme se entende o que seja poder político. Os professores apreendem esse saber na vida e na escola, em suas mais variadas formas e graus (cf. Janotti, Prado, \& Oliveira, 2006).

O Saber Profissional, no caso dos profissionais do magistério, tem na prática docente a sua fonte principal. Se for certo que ninguém nasce professor ou professora, mas vai se fazendo professor em variadas situações e experiências, também parece ser correto afirmar que "ser professor" só é possível mediante o envolvimento com os quefazeres docentes. Múltiplos são esses saberes, mas eles podem ser vistos nas perspectivas teórica, metodológica, técnica, política e prática, por exemplos. Aprende-se a ser 
professor mediante a vivência no meio profissional do magistério, bem como por meio da prática concreta de planejamento, execução e avaliação de ações de ensino (cf. Rancière, 2002).

O Saber Social refere-se ao conjunto de informações e conhecimentos teóricos e práticos que incluem atitudes, exercícios de poder, habilidades, posturas, relações humanas diversificadas, valores e vínculos que homens e mulheres vivenciam ao longo da existência. São aprendidos pelos professores na medida em que vivenciam, nas instâncias institucionais e fora delas, aquelas interações que os humanos estabelecem na família, na escola, no trabalho, na universidade e na sociedade, entre outras (cf. Charlot, 2000).

O Saber Vivencial tem sua fonte na admiração e no espanto do ser humano diante da vida, os quais Ihe pregam a problematização que pode ser formulada pelas chamadas "perguntas perenes": Quem sou? De onde vim? Para onde vou? A vida merece ser vivida? Esse saber também brota da vida mesma, apreendido pelo professor e pela professora enquanto vivem naturalmente a existência, na espontaneidade implicada no processo de educabilidade por meio do qual cada um se faz homem, mulher, e, por conseguinte, professor ou professora (cf. Savater, 2001).

É desse amplo conjunto de informações, conhecimentos e saberes que os professores e as professoras podem extrair o sentido e significado para tempo, pensamento e sociedade, essa em meio à qual são chamados a desenvolver a práxis educativa intencionada, preferentemente crítica e transformadora da realidade para um melhor, no sentido da humanização da vida particular e social.

\section{Conclusão}

Pensar sobre a práxis educativa considerando o tempo, o pensamento e a sociedade é uma tarefa que requer de nós esse esforço para encararmos a educação do tempo presente como aquela por meio da qual os sujeitos dessa prática podem problematizar: $O$ modelo societário no qual nos vemos inseridos satisfaz as exigências de uma sociedade baseada nos valores da justiça e da liberdade? Como, na condição de educadores, podemos atuar com vistas para o questionamento dos modelos societários produzidos até hoje e que nos desafiam para a sua necessária superação? O estilo 
existencial que reservamos ao ser humano, a título de finalidade da educação, atende aos princípios de uma convivialidade social fundada na solidariedade possível ao homem e à mulher concretos, com os quais convivemos?

A postura crítica aqui preconizada nos leva a colocar em questão o centralismo do coletivismo de certas concepções socialistas e o individualismo isolacionista da ideologia liberal capitalista, defensores de práticas sociais nas quais o humano emerge instrumentalizado no "para isso" e "para aquilo", jamais para ele próprio. Para tanto, todo o conteúdo exposto anteriormente sugere-nos a consideração da práxis educativa como aquela sustentada por uma epistemicidade preferencialmente aberta (docência práxica que envolve Saber Antropológico, Saber Cultural, Saber Econômico, Saber Epistêmico, Saber Ético, Saber Ideológico, Saber Político, Saber Profissional, Saber Social e Saber Vivencial, como foi dito) e que faça frente às atuais necessidades humanas, liberta de pólos extremos e de reducionismos míopes. Nesse processo, parecem superadas as posturas que isolam e centralizam o aluno, tanto quanto aquelas que dão centralidade apenas à figura do professor, dando lugar ao fortalecimento de uma práxis educativa centrada na relação entre professor-aluno-alunos.

Uma abordagem da práxis educativa coerente com os desafios que nos batem à porta requer que pensemos em termos de uma concepção teórica e prática docente que valorize uma pedagogia relacional, interacional e vinculadora de seres humanos. Ora, "relação" implica mobilização de cotas de poder particulares, grupais ou coletivas. E o poder compreendido não como uma coisa, ou concentrado em alguma instância institucional da sociedade, mas destituído de essência universal, como algo constituído de formas díspares, heterogêneas e em constante transformação (cf. Foucault, 1979, 1987).

E, aí, nessa práxis educativa, vale a indignação diante das formas que centralizam o poder para melhor controlar, disciplinar e modelar os seres humanos em um sentido que nega o caráter dinâmico e transformador da própria vida. Em seguida, o entendimento sobre o professor e a professora que podem lidar com os bens epistêmicos da cultura sistematizada são aqueles capazes de problematizar o real vivido, colocando de lado as pressuposições estagnantes em um passado que já não nos satisfaz, bem como aqueles entendimentos de que a vida se resolveria na extração de 
presumíveis valores plantados num futuro remoto, pós-terrenidade ou existencialidade.

Pensar, então, é enfrentar os estados de coisas que são mantidos visando à cristalização de ideologias que justificam práticas educativas meramente reprodutoras. O professor e a professora, nesse contexto, portadores de saberes vários, são aqueles sujeitos sociais que olham o mundo e a sociedade e, científica e filosoficamente, podem afirmar como eles são, tanto quanto aqueles sujeitos que mantêm a disposição de afirmar como o mundo e a sociedade não deveriam ser. E de, entre um movimento e outro, cunhar a práxis educativa voltada para o alcance de um modo humano de ser no mundo lastreado na justiça e na liberdade. Isso, ao que parece, pode nos colocar na vivência de um processo que articule, coerentemente, o tempo, o pensamento e a sociedade por meio de uma práxis educativa alimentada pela inconformidade.

\section{Referências}

Abbagnano, N. (1998). Dicionário de Filosofia. São Paulo: Martins Fontes.

Agostinho, A. (1986). Confissões. São Paulo: Nova Cultural.

Althusser, L. (1983). Aparelhos ideológicos de Estado. Rio de Janeiro: Graal.

Andrade, C. D. (1983). Poesia e prosa. Rio de Janeiro: Nova Aguilar.

Bergson, H. (1964). A evolução criadora. Lisboa: Edições 70.

Brandão, J. S. (2004). Mitologia grega. Petrópolis: Vozes.

Buzzi, A. R. (2003). Introdução ao pensar: O ser, o conhecimento, a linguagem (33 ${ }^{\mathrm{a}}$ ed.). Petrópolis: Vozes.

Cabanas, J. M. Q. (1996). Educación moral y valores. Revista de Ciencias de la Educación, 166.

Charlot, B. (2000). Da relação com o saber: Elementos para uma teoria. Porto Alegre: Artmed.

Chauí, M. (2003). O que é ideologia ( $2^{\mathrm{a}}$ ed.). São Paulo: Brasiliense.

Descartes, R. (1997). Princípios de Filosofia. Lisboa: Edições 70.

Durozoi, G., \& Roussel, A. (1993). Dicionário de Filosofia. Campinas: Papirus.

Figueiredo, V. (2007). Filósofos na sala de aula. São Paulo: Berlendis \& Vertecchia.

Forquin, J. C. (1992). Saberes escolares, imperativos didáticos e dinâmicas sociais. Porto Alegre: Teoria \& Educação.

Forquin, J. C. (1993). Escola e cultura: As bases sociais e epistemológicas do conhecimento escolar. Porto Alegre: Artes Médicas. 


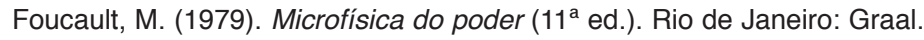

Foucault, M. (1987). Vigiar e punir: Nascimento da prisão. Petrópolis: Vozes.

Freire, P. (1978). Pedagogia do oprimido ( $3^{\mathrm{a}}$ ed.). Rio de Janeiro: Paz e Terra.

Freire, P. (1987). Educação e mudança. Rio de Janeiro: Paz e Terra.

Freire, P. (1997). Pedagogia da autonomia: Saberes necessários à prática educativa. São Paulo: Paz e Terra.

Garrido, S. (Org.). (1999). Saberes pedagógicos e atividade docente. São Paulo: Cortez.

Giacoia Júnior, O. (2009). Pequeno dicionário de Filosofia contemporânea. São Paulo: Publifolha.

Gramsci, A. (1981). Os intelectuais e a organização da cultura. Rio de Janeiro: Civilização Brasileira.

Hegenberg, L. (1976). Explicações científicas: Introdução à filosofia da ciência (2a ed.). São Paulo: EPU/EDUSP.

Heidegger, M. (2001). Ser e tempo ( $8^{\mathrm{a}}$ ed.). Petrópolis: Vozes.

Hessen, J. (1980). Teoria do conhecimento (7 $7^{\mathrm{a}}$ ed.). Coimbra: Arménio Amado.

Husserl, E. (2006). Idéias para uma fenomenologia pura e para uma filosofia fenomenológica. Aparecida: Idéias \& Letras.

Jameson, F. (1995). As marcas do visível. Rio de Janeiro: Graal.

Janotti, M. L. M., Prado, M. L. C., \& Oliveira, C. H. de S. (Orgs.). (2006). A história na política, a política na história. São Paulo: Alameda.

Kant, I. (1985). Crítica da razão pura. Lisboa: Calouste Gulbenkian.

Konder, L. (1993). O futuro da filosofia da práxis. Rio de Janeiro: Paz e Terra.

Laplantine, F. (1989). Aprender antropologia. São Paulo: Brasiliense.

Libâneo, J. C. (2002). Didática. São Paulo: Contexto.

Libâneo, J. C., Oliveira, J. F., \& Toshi, M. S. (2004). Educação escolar: Políticas, estrutura e organização. São Paulo: Cortez.

Macpherson, C. B. (1979). A teoria política do individualismo possessivo (de Hobbes a Locke). Rio de Janeiro: Paz e Terra.

Marx, K. (1845). Teses sobre Feuerbach. Ridendo Castigat Mores: eBooks Brasil. Disponível em http://www.adelinotorres.com/historia/Karl\%20Marx-Teses\% 20sobre\%20Feuerbach.pdf (acesso em 10 de março de 2011).

Marx, K. (1982). O capital: Crítica da economia política (7a ed.). São Paulo: Difel.

Marx, K., \& Engels, F. (1987). A ideologia alemã. São Paulo: Hucitec.

Monteiro, A. M. C. (2001). Professores: Entre saberes e práticas. Educação e Sociedade, 22(74), 121-142.

Nóvoa, A. (2005). Dilemas dos professores: A comunidade, a autonomia, o conhecimento. In D. S. Araújo, M. D. Braga \& Y. C. Capuzzo (Orgs.), Perspectivas para a formação de professores: Contribuições do IV Seminário das Licenciaturas (Anais) (pp. 11-28). Goiânia: Editora da UCG.

Nóvoa, A. (Org.). (1991). Profissão professor. Porto: Porto Editora. 
Oliveira, A. S. (1996). Estágios da consciência segundo Paulo Freire. In Educação: Redes que capturam caminhos que se abrem (pp. 35-48). Vitória: EDUFES.

Perrenoud, P. (2000). Dez novas competências para ensinar. Porto Alegre: Artmed.

Rancière, J. (2002). O mestre ignorante: Cinco lições sobre emancipação intelectual. Belo Horizonte: Autêntica.

Rocker, R. (1946). As idéias absolutistas no socialismo. São Paulo: Sagitário.

Romanovski, J. P. (2007). Formação e profissionalização docente (3 ${ }^{a}$ ed.). Curitiba: IBPEX.

Savater, F. (1998). O valor de educar. São Paulo: Martins Fontes.

Savater, F. (2001). As perguntas da vida. São Paulo: Martins Fontes.

Saviani, N. (2003). Saber escolar, currículo e didática. São Paulo: Autores Associados.

Schumpeter, J. (1982). Teoria do desenvolvimento econômico: Uma investigação sobre lucros, capital, crédito, juro e o ciclo econômico. São Paulo: Abril Cultural.

Tardif, M., \& Raimond, D. (2000). Saberes, tempo e aprendizagem do trabalho no magistério. Educação \& Sociedade, 21(73), 209-244. Disponível em http://www.scielo.br/pdf/es/v21n73/4214.pdf (acesso em 15 de setembro de 2009).

Vázquez, A. S. (1977). Filosofia da práxis. Rio de Janeiro: Paz e Terra. 
EDUCATIONAL PRACTICE: TIME, THOUGHT AND SOCIETY

\begin{abstract}
This text discusses Educational praxis, conceived in the articulation of time, thought and society concepts. This essay is developed in the light of conceptual research guidelines. It advocates the concern about the education of real men and women, not the ones ideally conceived. We analyze the capitalist and socialist societal models facing the challenge of creating a societal model and an existential style based on justice and freedom values, ultimate arguments for teachers mobilize the knowledge they hold in actual teaching and learning situations.
\end{abstract}

Keywords

Educational praxis; Time; Thought; Society 
PRAXIS EDUCATIVA: TIEMPO, PENSAMIENTO Y SOCIEDAD

\section{Resumen}

El tema de este trabajo es la praxis educativa, concebida por la articulación de los conceptos de tiempo, pensamiento y sociedad. Se llevó a cabo a la luz de las directivas de la investigación conceptual. Defiende la preocupación con la educación del presente para el hombre y de la mujer en realidad, no idealmente diseñados. El trabajo analiza los modelos corporativos capitalistas y socialistas y preconiza enfrentar al reto de crear un modelo corporativo y un estilo existencial basados en los valores de la justicia y de la libertad, qué son las justificaciones últimas para que el maestro e la maestra puedan movilizar los conocimientos que poseen en situaciones reales de enseñanza y aprendizaje.

Palabras-clave

Praxis educativa; Tiempo; Pensamiento; Sociedad;

Recebido em Junho/2011

Aceite para publicação em Julho/2012

\footnotetext{
Toda a correspondência relativa a este artigo deve ser enviada para: Wilson Correia, Universidade Federal do Recôncavo da Bahia, Centro de Formação de Professores de Amargosa, Av. Nestor de Melo Pita, 535 centro, Amargosa, BA, Brasil. E-mail: wilsoncorreia@ufrb.edu.br; Telef.: +55 753634 3042
} 